\title{
Predictor Breast Feeding Self Efficacy in First Week Post-
}

\section{Partum}

\section{Anggorowati A*, Naviati E, Sudarmiati S, Asmara FY and Susilowati D \\ Nursing Department Faculty of Medicine, Diponegoro University, Indonesia}

*Corresponding author: Anggorowati Anggorowati, Department of Nursing, Diponegoro University, Indonesia, Tel: +6281805889295; Email:

\section{Research Article \\ Volume 3 Issue 6}

Received Date: November 20, 2019

Published Date: December 23, 2019

DOI: $10.23880 /$ nhij-16000211

anggorowati@fk.undip.ac.id

\section{Abstract}

Background: The success of breastfeeding mothers is demonstrated by exclusive breastfeeding for six months. Selfefficacy of breastfeeding mothers determines the success of exclusive breastfeeding.

Objective: The objective of the study was to analyze the characteristics of mothers with regard to predicted self-efficacy.

Methods: Cross-sectional research in first-week postpartum, normal delivery, live birth. Sample taken by purposive sampling on 44 postpartum mothers in Public Health Center and hospital in Semarang area. Data were analyzed by linear regression.

Results: The results of the study were mostly high school educated women (56.8\%), hospital birth (52.3\%), there were self-efficacy differences on the first and third days $(\mathrm{p}=0,032)$. Strong characteristic factors influenced the self-efficacy of early breastfeeding initiation $(p=0,002)$ and gravida $(p=0,013)$.

Conclusion: In postpartum women should be done early breast-feeding intiation and before the third day should be given education, family support and nurse / midwife for exclusive breastfeeding.

Keywords: Post-partum mothers; Breastfeeding self-efficacy; Early breastfeeding initiation

\section{Introduction}

The mother's ability to breastfeed is demonstrated by the production and release of breast milk that is affected by the hormone prolactin and oxytocin. The letdown reflex is the response of the nervous system that causes breastfeeding cells to contract so that the milk inside it is squeezed out, flowing along the milk line, and out through the nipple. The new letdown reflex works when it gets a command from the hormone oxytocin. High levels of the hormone oxytocin maximize the number of breast milk containment [1].

The postpartum mother has the task of breastfeeding her baby exclusively for 6 months continuing for up to 2 years. Benefits obtained by breastfeeding the baby, among others, for the mother alone can accelerate the process of uterine involution, reduce the incidence of puerperal bleeding, reduce breast cancer risk. For the baby's own effective breastfeeding is beneficial to meet the nutrients, 


\section{Nursing \& Healthcare International Journal}

bonding relationships with his mother, improve the body's defences [2].

Every postpartum has the potential to exclusively breastfeed but some conditions make the mother unable to breastfeed. Self-efficacy of breastfeeding is one of the factors that influence mothers to have confidence to breastfeed. Confidence for breastfeeding will stimulate the hormone oxytocin so as to improve the smoothness of breast milk.

The experience at the time of giving mother's own selfefficacy. Significant developments occur during the first weeks of the puerperium. Engorgement occured on the day 1-3 childbirth, the period began to produce milk. On the first day some mothers become less confident because the milk produced is not smooth. Therefore we need to know the difference of self-efficacy of breastfeeding mother on the first day and the third day.

\section{Methods}

Cross-sectional studies were performed by giving selfefficacy breastfeeding questionnaires to postpartum women with normal delivery. The self-efficacy breastfeeding questionnaire consisted of 12 statements with a maximum score of 48 . The efficacy of breastfeeding was good when the score was over 36. Inclusion criteria: first postpartum mother, normal delivery, live birth. Sampling purposively taken at Public Health Center in Semarang and RS Semarang was obtained by 44 postpartum mothers. The study was conducted for 2 months in 2017. Data were analyzed by linear regression. This study has been approved by the Medical Faculty Diponegoro University Ethic Committee (Tables $1 \& 2$ ).

\section{Results}

\begin{tabular}{|c|c|c|c|}
\hline Variable & Mean (min-max) & F (\%) & $\mathbf{P}$ \\
\hline Age & \multirow[t]{6}{*}{$28,18(17-43)$} & & 0,050 \\
\hline Education & & & \\
\hline Elementary school & & $2(4,5 \%)$ & 0,091 \\
\hline Yunior High School & & $14(31,8 \%)$ & \\
\hline Senior High School & & $25(56,8 \%)$ & \\
\hline University & & $3(6,8 \%)$ & \\
\hline \multicolumn{4}{|l|}{ Worker } \\
\hline Yes & & $16(36,4 \%)$ & 0,476 \\
\hline No & & $28(63,6 \%)$ & \\
\hline \multicolumn{4}{|l|}{ Place of birth } \\
\hline \multicolumn{4}{|l|}{ Public Health Center } \\
\hline \multicolumn{4}{|c|}{$23(52,3 \%)$} \\
\hline Maternity Hospital & & $6(13,6 \%)$ & \\
\hline \multicolumn{4}{|l|}{ Early Breastfeeding Initiation } \\
\hline Yes & & $19(43,2 \%)$ & \\
\hline 0,002 & & & 0,002 \\
\hline \multicolumn{4}{|l|}{ Gravida } \\
\hline Birth weight & $3047(1800-4100)$ & & 0,211 \\
\hline
\end{tabular}

Table 1: Characteristics of the puerperal mother and her relationship with Self Efficacy Breastfeeding in First Week.

Characteristics of postpartum mostly high school educated, mother not working, at the time of early breastfeeding initiation and weight of normal baby. Age, early breastfeeding initiation, gravida are associated with the efficacy of breastfeeding. While education, occupation, delivery and weight are not related to the efficacy of breastfeeding.

\begin{tabular}{|c|c|c|c|}
\hline Variable & First Day Post Partum & Thirth Days Post Partum & p value \\
\hline Breast Feeding Self Efficacy & $35(22-48)$ & $43(33-48)$ & 0,032 \\
\hline
\end{tabular}

Table 2: Breast Feeding Self Efficacy on First Week Post-Partum. 


\section{Nursing \& Healthcare International Journal}

The result of linear regression analysis on Table 3.

\begin{tabular}{|c|c|c|c|c|c|}
\hline \multirow{2}{*}{ Model } & \multicolumn{2}{|c|}{ Unstandardized Coefficients } & \multirow{2}{*}{$\begin{array}{c}\text { Standardized Coefficients } \\
\text { Beta }\end{array}$} & \multirow{2}{*}{$\mathbf{t}$} & \multirow{2}{*}{ Sig } \\
\hline & B & Std Error & & & \\
\hline 1. (Constant) & 23.993 & 3.408 & & 7.041 & 0 \\
\hline Age & 0.036 & 0.151 & 0.049 & 0.236 & 0.815 \\
\hline EAB & 4.708 & 1.314 & 0.466 & 3.583 & 0.001 \\
\hline Gravida & 1.348 & 1.114 & 0.252 & 1.21 & 0.233 \\
\hline 2.(Constant) & 24.542 & 2.457 & & 9.991 & 0 \\
\hline EAB & 4.721 & 1.298 & 0.467 & 3.638 & 0.001 \\
\hline Gravida & 1.553 & 0.688 & 0.29 & 2.258 & 0.029 \\
\hline
\end{tabular}

Table 3: Predictor Breast Feeding Self Efficacy Linear regression analysis.

The result of regression analysis of fit model that is model 2, the variable that have influence to breast feeding self-efficacy that is early breastfeeding initiation and gravida, regression equation that is:

Breastfeeding Self Efficacy $=24.54+4.72 *$ IMD $+1.55 *$ gravida

Value R2 $=0.331$, this equation shows the obtained regression model can explain $33.1 \%$ efficacy of breastfeeding. The early breastfeeding initiation variable is the largest role in the efficacy of breastfeeding (Beta = $0.467)$.

\section{Discussion}

Breastfeeding self-efficacy is a postpartum confidence to be able to breastfeed to determine the success of breastfeeding. The perception that breast milk is not enough is still one of the problems in breastfeeding mothers [3].

The results showed that there were efficacy differences on the first and third days of the puerperium period. An increase of score 6 on the third day. Breast feeding Self-efficacy becomes a predictor of the length of breastfeeding mother [4]. The more frequency breastfeeding mothers the more milk production increases. The results showed that 30-40 mothers in the frequency of breastfeeding is still less than 10 times a day. It is risky for the production of breast milk is less than the need. Although self-efficacy between the control and intervention groups on the third day there was no significant difference, based on previous studies that the use of the Oxytocin stimulant may increase the volume of $23 \mathrm{ml}$ of milk [5].

The expectation of continuous use until exclusive breastfeeding indicators can be achieved. The self-efficacy differences appear to result when the intervention is given 4 weeks, as was the previous study on breastfeeding self-efficacy intervention [6]. The duration of intervention in this study that was only 3 days may result in insignificant results in treated and untreated groups.

The early breastfeeding initiation variable has the greatest role in the efficacy of breastfeeding, but it is also gravida. In mothers whose first 30 minutes of breastfeeding had self-efficacy and a higher LACTH score [7]. Early breastfeeding initiation provides an opportunity for the baby to seek his own mother's nipple for one hour. The baby reflex will look for his mother's nipple. This study is in line with the Guimaraes study that breastfeeding in the first hour after delivery is related to the level of self-efficacy. In the puerperal mother of other related issues is the support of grandmother [8]. Another study showed that breastfeeding initiation became a selfefficacy predictor such as Yang done [9]. In addition to breastfeeding initiation the predictors of intention of breastfeeding, support from husband, support from nurses / midwives, attending antenatal breastfeeding classes, time from childbirth to initiate breastfeeding and previous breast feeding experience. Self-efficacy of high puerperium moms in infants who are exposed in the first hour after delivery.

This study shows that gravida is related to the selfefficacy of breastfeeding mothers, as is the study of Ku CM [10]. It also deals with family income. Study Tavares show that age related to self-efficacy [11]. The increasing age of self-efficacy is higher [12]. The findings also showed no significant association between per capita income and breastfeeding self-efficacy [12]. The same result was found in studies carried out in England and Brazil, which did not identify such statistical difference either $[11,13,14]$. However, in Turkey there was a statistically significant difference between these variables $(p=0.001)$, 


\section{Nursing \& Healthcare International Journal}

suggesting that low 7 income mothers are vulnerable to poor outcomes in terms of breastfeeding due to decreased self-efficacy [15].

\section{Conclusion}

On the third day of self-efficacy breastfeeding mothers are higher than at the first day of the puerperium. The postpartum period of the first week determines the success of the mother during breastfeeding. It needs to be educated and social support from family and health officer (nurse / midwife) to improve self-efficacy of breastfeeding in postpartum.

\section{References}

1. Riordan J, Wambach K (2010) Breastfeeding and Human Lactation. $4^{\text {th }}(\mathrm{edn})$, Canada: Jones and Barlett LLC.

2. Pilliteri A (2003) Maternal and Child Health Nursing: Care of the Childbearing \& Childrearing Family. $4^{\text {th }}$ (Edn.), Philadelphia: Lippincott Williams \& Wilkins.

3. Sunanda B, Nayak SA (2017) Descriptive Study to Identify the Breastfeeding Problems among Postnatal Mothers in Justice KS Hegde Hospital, Mangalore. Int J Nurs Educ 9(3).

4. Pollard D, Guill M, Hanover N, Medical R (2009) The Relationship between Baseline Self-Efficacy and Breastfeeding Duration. South Online J Nurs Res 9(4).

5. Anggorowati A, Sutadi H, Setyowati S, Koestoer RA (2016) Effects of Acupoint Stimulation with Digital Massager of Oxytocin on the Breast Milk Production of Working Mothers. Nurse Media J Nurs 6(2): 91100.

6. Otsuka K, Taguri M, Dennis CL, Wakutani K, Awano M, et al. (2014) Effectiveness of a Breastfeeding Selfefficacy Intervention: Do Hospital Practices Make a Difference? 18(1): 296-306.

7. Gerçek E, Sarıkaya Karabudak S, Ardıç Çelik N, Saruhan A (2017) The relationship between breastfeeding self-efficacy and LATCH scores and affecting factors. J Clin Nurs 26(7-8): 994-1004.

8. Guimareas C, Conde RG, Gomes Sponholz FA, Oria MOB, Monteiro JCS (2017) Factors related with breastfeeding self-efficacy immediate after birth in puerperal adolescents. Acta Paul Enfermagem 30(1): 109-115.

9. Yang X, Gao LL, Ip WY, Sally Chan WC (2016) Predictors of breast feeding self-efficacy in the immediate postpartum period: A cross-sectional study. Midwifery 41:1-8.

10. Ku C, Chow S (2010) Factors influencing the practice of exclusive breastfeeding among Hongkong Chinese women: a quistionnaire survey. J Clin Nurs 19(17-18): 2434-2445.

11. Rodrigues AP, Padoin SM de M, Paula CC de Í, Souza E de $O$ (2015) Influence of sociodemographic and behavioral conditions on self-efficacy in breastfeeding: a cross-sectional study. Online Brazilian J Nurs 14(3).

12. Tavares M, Aires J, Dodt R, Joventino E, Oriá MOB X (2010) Application of Breastfeeding Self-Efficacy Scale-Short Form to post-partum women in roomingin care: a descriptive study. Online Brazilian J Nurs $9(1)$.

13. McCarter Spaulding D, Gore R (2009) Breastfeeding Self $\neg$ Efficacy in Women of African Descent. J Obstet Gynecol Neonatal Nurs 38(2): 230-243.

14. Zubaran C, Foresti K, Schumacher M, Thorell MR, Amoretti A, et al. (2010) The Portuguese Version of the Breastfeeding Self $\neg$ Efficacy Scale-Short Form. J Hum Lact, 26(3): 297-303.

15. Aluş Tokat M, Okumuş H, Dennis CL (2010) Translation and psychometric assessment of the Breastfeeding Self-Efficacy Scale - Short Form among pregnant and postpartum women in Turkey. Midwifery 26(1): 10-18. 